\title{
EDITORIAL
}

\section{Congreso chileno virtual de radiología: Una mirada en retrospectiva}

\author{
Juan Pablo Cruz Quiroga ${ }^{*}$
}

1. Radiólogo. Pontificia Universidad Católica de Chile. Santiago, Chile.

Este artículo tiene como objetivo acercar a la comunidad el proceso de organización del congreso chileno virtual de radiología 2020, y finalmente realizar una pequeña reflexión tras el evento.

El contexto mundial actual ha forzado a todas las áreas a innovar e implementar tecnologías de teletrabajo. Este año el directorio de la sociedad, al ver una inminente cancelación de nuestro evento debido a las crecientes restricciones, decidió sumarse a la opción tecnológica y realizar el congreso en forma virtual.

Inmediatamente nos enfrentamos a múltiples desafíos. Faltaban pocos meses para la fecha, considerando que normalmente estos eventos se planifican con al menos un año de anticipación. Existía también una barrera tecnológica que vencer tanto a nivel de los expositores como a nivel de los usuarios o, en este caso, asistentes. Era necesario buscar un sistema amigable, intuitivo o, como se dice en el ámbito tecnológico, "usable". Otra dificultad era la reestructuración de la participación de las empresas auspiciadoras, ya que su intervención cambiaba radicalmente al no existir posibilidad de interacción presencial.

Debíamos buscar rápidamente alguna empresa organizadora de eventos virtuales que nos ayudara a cumplir con lo planteado, sin dejar de lado los aspectos técnicos necesarios.

- Debíamos considerar un adecuado tamaño del servidor que aloje el sitio web para que no se viera afectado su rendimiento por el número de solicitudes simultáneas y la magnitud del tráfico. Nuestro objetivo fue al menos 1.000, idealmente 10.000 conexiones simultáneas. Debíamos ser optimistas.

- Una plataforma de streaming que cumpliera con una calidad de imagen óptima, muy necesaria en nuestro rubro. Tras un estudio de las opciones disponibles nos propusimos 1080p.

- La existencia de un chat que nos permitiera conservar algún grado de la interacción que habitualmente ocurre durante las exposiciones, con opción de moderación.

- Debía existir también la posibilidad de publicar trabajos científicos, para no perder el rol que cumple nuestro congreso.

Todas estas exigencias se presentaban en un contexto de incertidumbre, tanto en la asistencia como en el resultado y calidad de ejecución del evento. Sumado al contexto de la pandemia estaba la postergación de convenios de auspicio, la mala situación económica de muchos socios y el planteamiento de reducir la cuota social, lo que nos hacia trabajar con un presupuesto limitado.

Por supuesto, ninguna solución era a la medida y debían estudiarse y desarrollarse muchos de nuestros requerimientos. Tras múltiples reuniones con diversas empresas, se decidió trabajar con una con la que ya teníamos historia, dado la buena disposición que mostró de aventurarnos en este nuevo camino.

La organización del programa científico tampoco fue sencilla. El congreso sería más corto en extensión y en número de charlas, por lo que planteamos un congreso intenso, de alto nivel. Se recurrió, bajo nuestra estructura organizacional, a los directores de capítulos quienes aceptaron cooperar desinteresadamente. De esta forma, fue posible contar con un programa de excelente calidad y expositores de elite, quedando en evidencia la amplia red de contacto que existe entre los radiólogos chilenos y la comunidad internacional, así como la buena relación existente con las sociedades amigas.

Finalmente se cumplió con creces lo esperado. Tuvimos 15 conferencistas nacionales, 20 internacionales, 8 simposios de empresas, en un total de 46 conferencias. Participaron personas de 9 países. Contamos con la ayuda de 22 empresas auspiciadoras y 11 sociedades amigas. Fueron 815 asistentes con amplia concurrencia desde regiones y conexiones desde el extranjero, destacando la alta asistencia a cada módulo. Se presentaron 24 trabajos en modalidad de videopresentación, y fueron publicados cerca de 100 pósters virtuales. A nuestro encuentro de residentes asistieron alrededor de 130 personas.

Entre las ventajas pudimos observar la participación de expositores de renombre internacional de forma menos engorrosa, al no tener que viajar ni bloquear largos períodos de sus agendas. Mayor asistencia desde regiones, debido a la continuidad laboral e inexistente tiempo de traslado. También cabe destacar, que al nacer de un formato diseñado para la "pantalla chica", las presentaciones se encontraban en un formato optimizado para su almacenaje en nuestra videoteca. 
No podemos hacer vista ciega a las desventajas de la modalidad virtual. El trato fue bastante más impersonal, hubo drástica disminución de la interacción social y existió escasa y a ratos nula interacción con el expositor, puntos que sin duda deben ser tratados dirigidamente en caso de repetir la modalidad.

A modo de conclusión se hace necesario plantear una forma de juntar lo mejor de ambas modalidades, la posibilidad de realizar a futuro eventos "híbridos", con formato presencial habitual y manteniendo la posibilidad de asistir de forma remota permitiendo participar a los radiólogos de regiones, a quienes deban mantener continuidad de sus funciones y a colegas extranjeros que deseen disfrutar de nuestro congreso.

Cruz JP. Congreso chileno virtual de radiología: Una mirada en retrospectiva. Rev Chil Radiol 2020; $26(4): 131-132$. *Correo electrónico: Juan Pablo Cruz Q / jpcruz@med.puc.cl 